\title{
Neuropathic Orofacial Pain
}

\author{
Janina Christoforou ${ }^{1} \cdot$ Ramesh Balasubramaniam $^{1}$ - Gary D. Klasser ${ }^{2}$
}

Published online: 2 July 2015

(C) Springer International Publishing AG 2015

\begin{abstract}
Dental practitioners will be exposed to patients experiencing neuropathic pain of the orofacial region at some point in their careers. The pain can be distressing and affect quality of life. Therefore, an understanding of the clinical presentation, diagnosis, and management of neuropathic orofacial pain is essential since some patients will convincingly express this pain to be originating from a dental source. Neuropathic pain may be episodic such as trigeminal neuralgias, or continuous, which includes peripheral painful trigeminal traumatic neuropathy, persistent idiopathic facial pain, neuritis, and burning mouth syndrome. Research has revealed that these various neuropathic pains often have specific treatment modalities. Hence, establishing an accurate diagnosis and understanding the pathophysiology of the disorders are critical in the management of pain as these will avoid the initiation of unnecessary dental interventions.
\end{abstract}

Keywords Facial pain · Neuralgia · Trigeminal neuropathy · Burning mouth syndrome $\cdot$ Herpes zoster $\cdot$ Neuritis

\section{Introduction}

Neuropathic pain is defined as "pain caused by a lesion or disease of the somatosensory nervous system" [1]. For clinical

This article is part of the Topical Collection on Oral Medicine

Janina Christoforou janinachristoforou@gmail.com

1 School of Dentistry, University of Western Australia, Perth, Australia

2 School of Dentistry, Louisiana State University, New Orleans, Louisiana, USA purposes, based upon its temporal presentation, it may manifest as either continuous or episodic. Continuous neuropathic pains are pain disorders that have their origin in neural structures and are manifested as a constant, ongoing, and unremitting pain. Patients usually experience varying and fluctuating intensities of pain, often without total remission. The pain is often sensed in dental structures and has been referred to as atypical odontalgia [2] or phantom toothache [3]. Episodic neuropathic pain is characterized by sudden volleys of electric-like, severe, shooting pain lasting only a few seconds to several minutes and is referred to as neuralgia [4]. Often, there exists a perioral or intraoral trigger zone whereby nontraumatic stimuli such as light touch elicit a severe paroxysmal pain [4]. Unfortunately, due to the lack of recognition and understanding of these conditions, they are often treated by dental practitioners with ineffective dental interventions [5]. Therefore, it is incumbent on dental practitioners to gain an understanding of the pathophysiology, diagnosis, and management of these various neuropathic conditions to avoid unnecessary dental treatments.

\section{Mechanisms of Pain}

Pain is "An unpleasant sensory and emotional experience associated with actual or potential tissue damage, or described in terms of such damage" [1]. Noxious stimuli in the orofacial region depolarize high threshold polymodal nociceptors composed of free nerve endings described as $\mathrm{A} \delta$ (thinly myelinated) and C-fibers (unmyelinated), which may further be excited and sensitized by a neurochemical "soup" containing such products as prostaglandins, bradykinin, histamine, substance $\mathrm{P}$, etc. The fibers convey nociceptive stimuli along the trigeminal pathway to initially synapse with second-order neurons (wide dynamic and/or nociceptive specific) located in the 
nucleus caudalis of the trigeminal spinal tract nucleus in the brain stem. Within the nucleus caudalis, the signal can be subject to modulation (inhibition or facilitation). Secondorder fibers then cross the midline, undergo further modulatory processes, and ascend to synapse in the thalamus, which is involved in pain perception. Finally, the noxious impulse projects to the somatic sensory areas of the cerebral cortex, where there is discrimination and determination of the intensity of the nociceptive stimulus. The interpretation of the stimulus is influenced by cognitive-behavioral and affective-motivational factors (such as past experiences, anxiety), and hence, pain is recognized as a complex interaction of cognitive, affective, and sensory processes making it a "personal experience" [6].

\section{Trigeminal Neuralgia}

Trigeminal neuralgia (TN) is a paroxysmal pain involving one or more divisions of the trigeminal nerve distribution. Prevalence rates for TN are 1.5 cases per 10,000 [7] and vary significantly with age. Approximately $90 \%$ of patients with symptomatic presentation are over the age of 40 years with a typical onset between 60 and 70 years [7].

$\mathrm{TN}$ is classified into classical trigeminal neuralgia (paroxysmal or with associated persistent facial pain) and painful trigeminal neuropathy. The precise pathogenesis of both forms is unknown, but it is suspected that both peripheral and central nerve dysfunction play a role [8]. Possible etiologies include the compression of the trigeminal nerve root, demyelinating disorders, such as multiple sclerosis (MS) [9], neoplastic infiltration [10], and familial disorders, such as Charcot-MarieTooth disease [11], and secondary to herpetic infections [12].

Classical TN is considered idiopathic although it is commonly associated with chronic vascular compression of the trigeminal nerve at the root entry zone of the brain stem [8]. The superior cerebellar artery is most commonly involved [13]. The compression results in morphological changes in the nerve, such as distortion, deviation, groove formation, and/or atrophy of the nerve [14]. Individuals experiencing classical TN present with a unilateral, sharp, "electric shocklike" sensation in the distribution of one or more branches of the trigeminal nerve. Affected individuals experience refractory periods, which may last for weeks, months, or years. In comparison, painful $\mathrm{TN}$ is due to an identifiable structural lesion other than vascular compression, such as multiple sclerosis [9] and neoplastic conditions, i.e., meningioma [15] and amyloidoma [10]. These conditions result in similar morphological changes to the trigeminal nerve but are without a refractory period [16].

The peripheral nerve morphological changes occurring in both forms of $\mathrm{TN}$ lead to structural changes such as focal demyelination and afferent hyperexcitability and ectopic firing, forming part of the ignition hypothesis [17]. This may lead to central effects due to the hyperexcitability in the trigeminal brain stem complex and result in similar pain responses to nonnoxious as well as noxious stimuli. This correlates to the presence of allodynia manifested by individual trigger factors such as light touch, mild wind, toothbrushing, application of cosmetics, and shaving in those experiencing TN. Furthermore, a reduction in brain gray matter has been observed which correlates with greater TN duration [18], possibly representing a protective effect to chronic pain.

The diagnosis of TN is based on history and examination, which should include a cranial nerve examination. Also, a magnetic resonance imaging (MRI) and/or magnetic resonance angiography (MRA) of the brain and skull base is necessary to investigate possible vascular impingement and exclude intracranial pathosis.

First-line management for either form of TN is centrally acting medications. Carbamazepine provides the most predictable results [19], but it has a number of side effects with potentially serious adverse consequences. Other medications that have been trialed are presented in Table 1.

In refractory cases and where there have been no remission periods, surgical options are utilized. Microvascular decompression (MVD) is the first-line surgical option with initial pain relief in $88 \%$ of patients and stability for 9.7 years [20]. In classical TN, the vasculature, i.e., commonly the superior cerebellar artery, is in close proximity to the trigeminal nerve root (mostly occurring at the entrance of the nerve root entering the pons) resulting in demyelination of the sheath and altered neural signal propagation [21]. Teflon is placed to separate the nerve from the vessel [8].

Stereotactic strategies such as linear accelerators and gamma knives are a consideration in those patients who are poor candidates for surgical procedures. This is an ablative procedure and involves treating the trigeminal nerve with a single high dose of external beam radiation (70-90 Gy) delivering a dose to the proximal trigeminal root near the pons, resulting in focal axonal degeneration and necrosis [22].

Other ablative procedures include glycerol rhizotomy [23], cryotherapy [24], partial rhizotomy, and radiofrequency lesioning [25]. These procedures destroy neurons or their axons, thereby reducing the recruitment of ectopic neural activity. They are most commonly utilized when other options have failed or in individuals with TN associated with MS. A common adverse event of these procedures is a resultant paresthesia. An additional option to be considered when other surgical modalities have not been effective is percutaneous balloon compression [26]. This involves the insertion of a balloon into Meckel's cave, resulting in compression of the trigeminal ganglion once inflated. This interferes with the nerve's ability to transmit signals, resulting in mild sensory loss.

Ideal timing for surgical intervention is unknown, but a long-term cohort study [27] and patient satisfaction surveys 
Table 1 Medications used in the management of trigeminal neuralgia

\begin{tabular}{|c|c|c|c|}
\hline Medication & Dosage & Side effects & Efficacy \\
\hline Carbamazepine & $\begin{array}{l}\text { Started at } 300 \mathrm{mg} \text { and } \\
\text { maintenance at } \\
800-1600 \mathrm{mg} / \text { day [19] }\end{array}$ & $\begin{array}{l}\text { Leukopenia, aplastic anemia, } \\
\text { thrombocytopenia, drowsiness, } \\
\text { ataxia, rash, warfarin interaction, } \\
\text { abnormal liver function tests }\end{array}$ & $\begin{array}{l}\text { First-line treatment. Effectiveness can be reduced } \\
\text { over time, i.e., initial success in } 60 \% \text { of patients, } \\
\text { but by } 5-16 \text { years only, } 22 \% \text { were still showing } \\
\text { it to be effective [ } 95] \text {. }\end{array}$ \\
\hline Oxcarbazepine & $\begin{array}{l}\text { Started at } 600 \mathrm{mg} / \text { day and } \\
\text { maintenance at } \\
1200-1800 \mathrm{mg} / \text { day [19] }\end{array}$ & $\begin{array}{l}\text { Visual disturbance, difficulty } \\
\text { walking }\end{array}$ & $\begin{array}{l}\text { Second-line treatment. Trials have shown similar } \\
\text { efficacy to carbamazepine [96] but decreases } \\
\text { its effectiveness over time [27]. }\end{array}$ \\
\hline Lamotrigine & $\begin{array}{l}\text { Started at } 25 \mathrm{mg} / \text { day and } \\
\text { maintenance at } 200-400 \\
\mathrm{mg} / \text { day [19] }\end{array}$ & $\begin{array}{l}\text { Visual disturbance, nausea, } \\
\text { drowsiness, serious skin } \\
\text { rashes, and allergies }\end{array}$ & $\begin{array}{l}\text { Has been used in combination therapy with } \\
\text { carbamazepine and also as monotherapy [97] }\end{array}$ \\
\hline Baclofen & $\begin{array}{l}\text { Started at } 15 \mathrm{mg} / \text { day and } \\
\text { maintenance at } 60-80 \\
\text { mg/day [19] }\end{array}$ & $\begin{array}{l}\text { Confusion, withdrawal symptoms, } \\
\text { drowsiness, GI symptoms }\end{array}$ & $\begin{array}{l}\text { Mainly used in conjunction with other medication. } \\
\text { Increased pain relief when carbamazepine is } \\
\text { combined with baclofen [98], but only trials } \\
\text { with small sample size }\end{array}$ \\
\hline Gabapentin & $\begin{array}{l}\text { Started at } 150 \mathrm{mg} \text { and } \\
\text { maintenance at } 300-900 \\
\text { mg/day [99] }\end{array}$ & $\begin{array}{l}\text { Unsteadiness, fatigue, weight } \\
\text { gain }\end{array}$ & $\begin{array}{l}\text { Minimal evidence. Effective first- and second-line } \\
\text { treatment [99]; } 27 \% \text { experience complete or near } \\
\text { complete pain relief, and } 53 \% \text { experience no } \\
\text { relief [99]. }\end{array}$ \\
\hline Pregabalin & $\begin{array}{l}\text { Started at } 150 \mathrm{mg} \text { and } \\
\text { maintenance at } 150-600 \\
\text { mg/day [14] }\end{array}$ & $\begin{array}{l}\text { Dizziness, weight gain, } \\
\text { drowsiness }\end{array}$ & $\begin{array}{l}\text { Minimal evidence. Effectiveness in treatment has } \\
\text { been shown [100]. }\end{array}$ \\
\hline Topiramate & $\begin{array}{l}\text { Started at } 25 \mathrm{mg} \text { bid and } \\
\text { maintenance at } 100 \mathrm{mg} \\
\text { bid [101] }\end{array}$ & Nephrolithiasis, mood disruption & Effective in TN secondary to MS [101] \\
\hline Sumatriptan & 3 mg subcutaneously [102] & Hypertension, drowsiness & Success in refractory TN [102] \\
\hline Botulinum toxin $\mathrm{A}$ & $\begin{array}{l}25-75 \text { units transcutaneously } \\
\text { (7.5 units per injection site) } \\
{[103]}\end{array}$ & Headache & $\begin{array}{l}\text { Insufficient scientific evidence. Some success in } \\
\text { refractory cases [104] }\end{array}$ \\
\hline
\end{tabular}

[28] reported that patients with poor tolerability or nonresponsiveness to medication and without a remission period should consider a surgical option [19]. Relapses can also occur with surgical procedures, showing reduced long-term pain relief (Table 2).

\section{Glossopharyngeal Neuralgia}

Glossopharyngeal neuralgia (GPN) is characteristically a brief, unilateral, mild to moderate electric shock-like pain localized to the ear, base of the tongue, tonsillar fossa, or inferior to the angle of the mandible. Up to $25 \%$ of patients may report bilateral pain [29]. The pain is typically triggered by swallowing, talking, coughing, or yawning. The pathophysiology of GPN is unclear; however, as in TN, likely nerve compression results in demyelinated axons [30]. Cardiac dysrhythmias and syncope may occur due to vagus nerve stimulation [31]. The incidence of GPN in the general population has been reported to be 0.2 per 100,000 persons per year [29]. GPN may coexist with TN in $10-12 \%$ of cases [31, 32]. Similar to TN, a significant association between GPN and MS has been reported [32].
A computed tomography (CT) or MRI is necessary to assess for intracranial lesions or neurovascular compression. First-line therapy for GPN is carbamazepine (200-1200 mg/ day). Alternatively, oxcarbazepine (600-1800 mg/day) may be utilized [33]. Application of local anesthetic to the tonsillar and pharyngeal wall areas may prevent attacks for a few hours [31].

In refractory cases, MVD may be considered. Also, intracranial sectioning of the glossopharyngeal nerve and the upper rootlets of the vagus nerve may be attempted [34]. Gamma knife surgery appears to be useful and safe for patients as initial therapy or for those who have failed medical and other surgical treatments [35].

\section{Occipital Neuralgia}

Occipital neuralgia $(\mathrm{ON})$ is a unilateral or bilateral paroxysmal, shooting, or stabbing severe pain in the posterior part of the scalp, in the distribution of the greater, lesser, or third occipital nerves, sometimes accompanied by diminished sensation or dysesthesia and/or allodynia in the affected area and commonly associated with tenderness over the involved 
Table 2 Common surgical procedures used in the management of trigeminal neuralgia

\begin{tabular}{|c|c|}
\hline Procedure & Success \\
\hline $\begin{array}{l}\text { Microvascular } \\
\text { decompression }\end{array}$ & $\begin{array}{l}\text { First-line surgical option } \\
\text { Immediate pain relief in } 88 \% \text { of patients with } \\
73 \% \text { pain free with medication after } 1 \text { year } \\
\text { and stable to } 9.7 \text { years [20] }\end{array}$ \\
\hline $\begin{array}{l}\text { Balloon } \\
\text { compression [26] }\end{array}$ & $\begin{array}{l}\text { Considered when rejecting MVD after medical } \\
\text { management. Minimal invasiveness } \\
\text { Initial success rate of } 85 \% \text {, but from these } \\
\text { patients, it reduces to } 36 \% \text { after } 20 \text { months } \\
\text { [105]. }\end{array}$ \\
\hline Ablative procedures & $\begin{array}{l}\text { - Glycerol: Immediate pain relief but reduced } \\
\text { long-term success; immediate success of } \\
93 \% \text {, but after } 4 \text { years, } 50 \% \text { were still pain } \\
\text { free [106]. } \\
\text { - Cryotherapy [24]: Initial success rate of } 85 \% \text {, } \\
\text { but at } 2 \text { years, } 14.5 \% \text { are pain free }[107] \text {; } \\
\text { can be used in demyelinating disorders. } \\
\text { - Radiofrequency [25]: High initial pain relief } \\
\text { ( } 98 \% \text { ), but } 15-20 \% \text { show recurrence in } \\
12 \text { months and } 57.7 \% \text { are pain free after } \\
5 \text { years [108]. }\end{array}$ \\
\hline $\begin{array}{l}\text { Stereotactic } \\
\text { radiosurgical } \\
\text { procedures } \\
\text { - Gamma knife therapy } \\
\text { - Linear accelerator [22] }\end{array}$ & $\begin{array}{l}\text { Pain relief occurs within } 3 \text { months. Initial } \\
\text { success of } 75 \% \text { and } 50 \% \text { are pain free at } \\
3 \text { years [109]. }\end{array}$ \\
\hline
\end{tabular}

nerve(s). The exact pathophysiology for $\mathrm{ON}$ is uncertain; however, the neuralgia is often a result of direct damage or irritation to the occipital nerve or in its distribution due to trauma (including flexion-extension injuries), compression of the upper cervical roots by degenerative spine changes, and tumors involving the second and third cervical dorsal roots [36, 37]. Other possible mechanisms include localized infections or inflammation, gout, diabetes, and blood vessel inflammation. Furthermore, it is important to distinguish ON from occipital pain referred from the atlantoaxial or upper zygapophyseal joints or from sources located in neck muscles or their insertions [38]. Hence, imaging studies are necessary to exclude underlying pathological conditions. Management with injection of local anesthetics and corticosteroids may provide temporary and even long-term pain relief [39].

\section{Nervus Intermedius Neuralgia}

Nervus intermedius neuralgia (NIN) also known as facial nerve or geniculate neuralgia is a rare disorder characterized by brief paroxysms of severe pain felt deep in the auditory canal, sometimes radiating to the parieto-occipital region. It may develop without apparent cause or as a complication of herpes zoster (Ramsay Hunt syndrome) [40]. The pathophysiology of NIN is unclear; however, myelin sheath delamination is thought to play a role [41].

NIN is often precipitated by stimulation of an area in the posterior wall of the auditory canal and/or periauricular region. Disorders of lacrimation, salivation, and/or taste sometimes accompany the pain associated with NIN. It is important to rule out local ear disorders prior to providing a diagnosis of NIN. Medications used for TN may be trialed. Surgical procedures may involve sectioning of the nervus intermedius or chorda tympani nerves or MVD for pain relief [42].

\section{Superior Laryngeal Neuralgia}

Superior laryngeal neuralgia (SLN) is a rare condition with severe paroxysmal pain felt in the throat, submandibular region, or under the ear with duration of minutes to hours. Episodes of pain are precipitated by swallowing, straining the voice, or head turning, and referral from an area located on the lateral aspect of the throat overlying the hypothyroid membrane [43]. The pathophysiology for SLN is not well described but thought to be related to damage to the superior laryngeal nerve from a precedent viral infection, scarring from a surgical procedure such as a tonsillectomy, and chronic repetitive trauma to the larynx from singing, talking, or swallowing [44].

Medications traditionally used for TN may be effective. Surgical procedures utilizing repeated nerve blocks with high doses $(5-10 \%)$ of lidocaine have shown lasting effects [45]. These are administered lateral to the greater cornu of the hyoid to target the internal branch of the superior laryngeal nerve.

\section{Peripheral Painful Traumatic Trigeminal Neuropathy}

Peripheral painful traumatic trigeminal neuropathy (PPTTN) is defined as a spontaneous or stimulus-dependent pain or disturbed sensation, predominately affecting the receptive field of one or more divisions of the trigeminal nerve. The pain is moderate to severe in intensity and usually described as burning; however, it can be stabbing [46••]. Most cases are continuous but may be episodic (minutes to days). The pain distribution may spread with time due to central mechanisms but usually remains unilateral. Characteristics of the neuropathic pain are variable among individuals. This is due to a combination of environmental (reduced social support) [6], psychosocial (anxious, introverted personalities) [6], and genetic factors (polymorphism in the gene encoding serotonin transporter) $[6,46 \bullet \bullet$.

The neuropathy typically develops within 3 months of an identifiable, traumatic event to the painful area (localized pain) or relevant innervation (dermatomal pain) and is 
associated with clinically evident positive (hyperalgesia, allodynia) and/or negative (hypoesthesia, hypoalgesia) signs of trigeminal nerve dysfunction. The neuropathy may be due to major craniofacial injury or from minor oral interventions such as extractions, endodontic treatment, and implant placement $[46 \bullet \bullet, 47]$. The diagnosis is made after history, examination, and adjunctive investigations to exclude other disorders such as infections, neoplastic lesions, and iatrogenic nerve compression.

Following injury to the trigeminal branches, chronic pain develops in about $3-5 \%$ of patients [48]. This is due to the peripheral sensitization or activation of nociceptors from the release of inflammatory mediators from tissue injury and also increased pressure secondary to inflammation [49], which may then induce nerve damage resulting in neural dysfunction [50]. Repeated nociceptive sensory input leads to the establishment of central sensitization [46••]. In addition, during repair, there may be entrapment of a nerve in scar tissue with subsequent neuroma formation.

Management involves the use of various medications such as tricyclic antidepressants (TCA), serotonin norepinephrine reuptake inhibitors, and gabapentinoids [51]. These regimes can also be combined with various opioids [46••]. When the neuropathy is episodic (rather than chronic), a combination of a corticosteroid (prednisone $60 \mathrm{mg}$ daily) with pregabalin (150 mg twice daily) was found to be effective [52]. The efficacy of surgery remains unclear due to insufficient trials $[46 \bullet \bullet$.

\section{Persistent Idiopathic Facial Pain}

Persistent idiopathic facial pain (PIFP) refers to persistent extraoral and/or intraoral pain along the territory of the trigeminal nerve that does not fit the classic presentation of other cranial neuralgias or another disorder [53]. The pain is usually of long duration, lasting most of the day (if not continuous), is unilateral, and is without sensory loss or other physical signs [53]. It is described as a severe ache, crushing, or burning sensation, which is poorly localized. A distinguishing feature is constancy of pain and clinical characteristics usually remain unchanged for weeks, months, or years. Most patients with PIFP complain of other symptoms such as headache, neckache, backache, dermatitis, irritable bowel, and uterine bleeding [54]. The reported prevalence in the general population is $0.03-1.0 \%$ [53] and it is seen primarily in adult females.

The pathophysiology of PIFP is unknown but appears to be multifactorial and of heterogeneous origin. PIFP may be initiated by surgery or injuries to the face or oral cavity [2] or even a minor noxious event to the afferent trigeminal nerve fibers, which may result in deafferentation and long-term neuroplastic changes. There may be a psychogenic origin, since one third of affected patients also suffer from depression [55]. In addition, there is currently emerging evidence of a neurobiological origin, since differences have been shown between PIFP patients and healthy controls in respect to gray matter volume in central pain processing regions (decreased in the former) [56] and differences in neural blood flow patterns [57]. Furthermore, increased D2 receptor density in the putamen was shown by positron emission tomography (PET), reinforcing the relevance of dopaminergic neurotransmission in the modulation of pain perception in PIFP [58].

Establishing a diagnosis follows a process of elimination of other causes of facial pain based on information gathered through patient history, clinical examination, imaging, and adjunctive testing, as deemed appropriate.

The goal of therapy is to manage the pain effectively while giving rise to the fewest possible medication side effects. Optimal outcome may be achieved following a multidisciplinary approach employing a combination of pharmacological therapy and psychological counseling involving patient education, cognitive therapy, coping strategies, relaxation techniques, biofeedback, or psychotherapy [54]. Pharmacological management with antidepressants and anticonvulsants, which block sodiumchannels, can be trialed to manage the neuropathic component of the pain, and also anxiolytics, analgesics, and antiarrythmics may be considered [53]. Amitriptyline (25$100 \mathrm{mg} /$ day) is the primary choice [54]. Also, since PIFP often is comorbid with affective disorders, the combination of anticonvulsant and antidepressant medications is rational. Gabapentin (900-1800 mg/day) and pregabalin (150$300 \mathrm{mg} /$ day) and also topical formulations, such as lidocaine transdermal (5\%) anesthetic, may also be trialed [54].

When the pharmacological treatment lacks adequate efficacy, pulsed radiofrequency treatment of the sphenopalatine ganglion may be considered [54]. Unfortunately, pain usually relapses. Available data on alternative treatments are limited; hence, it is suggested that invasive treatment should be avoided.

\section{Peripheral Neuritis}

Peripheral neuritis may occur with chemical poisoning, autoimmunity, alcohol, or nutritional deficiencies resulting in inflammation of the nerve. Inflammation of the nerve may be due to direct pressure from edema or mediator secretion typically cytokines [59].

The most common clinical presentation is tactile allodynia given the dominant role of myelinated nerve fibers [50]. With some invasive dental procedures, transient perineural inflammation may occur and is typically asymptomatic. In other cases, such as with periapical inflammation or a misplaced dental implant associated with a nerve trunk, chronic symptoms may be apparent. Similarly, perineural inflammation, 
pain, and other abnormal sensations can occur with temporomandibular joint pathologies [60], paranasal sinusitis [61], or early malignancies [62].

Treatment should focus on the resolution of the etiology of the inflammation. Prompt administration of corticosteroids or nonsteroidal anti-inflammatory drugs may be beneficial [63].

\section{Herpes Zoster}

Herpes zoster (HZ) is clinically diagnosed by a painful vesicular rash appearing in a unilateral dermatome. It results from the reactivation of varicella zoster virus (VZV), which stays latent in the spinal and cranial sensory ganglia after primary infection. The virus causes inflammation and neural injury, which leads to peripheral sensitization. Although herpes zoster can occur at any age, most cases occur after the age of 50 with the incidence of complications also increasing with age, i.e., the development of postherpetic neuralgia (PHN) [64].

$\mathrm{HZ}$ occurs when the cellular immunity is reduced after a history of a VZV infection or vaccination. The current view is that due to the increase in vaccinations at a young age, there are minimal exposures, and consequently, there is not a renewal of the antibody count to VZV (herd immunity), consequently reducing the cellular immunity, hence increasing the onset of HZ [65]. Increased risk for VZV, due to immunity only reaching subthreshold levels, is present in individuals with autoimmune disease [66], cancer patients [67], transplant patients [68], the elderly [69], and those experiencing excessive stress [70]. It has been postulated that the vaccine for VZV decreases the morbidity associated with herpes zoster and the incidence of PHN [69]. The vaccine contains a live attenuated VZV, and according to the Center for Disease Control, it is recommended that patients aged 60 years and older should be vaccinated regardless of prior exposure to VZV [71].

$\mathrm{HZ}$ has a prodrome usually lasting $2-3$ days and up to a week, which correlates to the time taken by the virus to replicate and cause necrosis and inflammation in the dermatomal skin. The pain is variable and described as throbbing or burning and characteristically increases during the day and intensifies when tired or stressed.

When HZ is diagnosed, the duration and intensity of symptoms can be reduced with antiviral therapy [72]. In

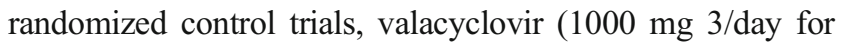
7 days) has been more effective than acyclovir $(800 \mathrm{mg} \mathrm{5/}$ day for 7-10 days) [73], and both should ideally be used within $72 \mathrm{~h}$ of rash onset. In ophthalmic HZ, there is risk for blindness, and hence, immediate referral to an ophthalmologist is necessary [74]. Supplemental medications, which can aid in pain management, include TCAs, opioids, and gabapentinoids [75].

\section{Postherpetic Neuralgia}

In approximately $10 \%$ of cases [76], HZ may progress to PHN. PHN may result in the loss of peripheral input from degeneration of afferent nerves, atrophy, or scarring of the spinal cord dorsal horn and dorsal root ganglion. This results in the development of spontaneous discharges in the deafferented central neurons, leading to intrinsic changes in the CNS, and consequently, produces constant pain in addition to mechanical allodynia in the area of sensory loss [77].

There are several predictive factors resulting in the development of PHN after an episode of HZ. Older age may be a possible factor because afferent nerve fibers may be compromised or have undergone degeneration of the myelin sheath and, hence, need less viral damage to present with PHN. Other factors include female gender, possibly due to the longer life expectancy. A more severe prodrome, a more intense acute pain, and a severe rash are also possible predictive factors, which may be due to a greater viral load and, hence, more tissue damage during the acute phase $[69,77,78]$, increasing the probability of progression to PHN.

Management is controversial as there is conflicting evidence on the use of antivirals in the acute phase to prevent PHN onset [77]. Anticonvulsants and antidepressants have also been utilized for the prevention of PHN [77, 78]. Several centrally acting medications have been trialed for the management of PHN.

Amitriptyline or nortriptyline [79] and gabapentin [79] or pregabalin [80] are considered first-line treatment options and may be given solely or in conjunction with other medications. Opioids (oxycodone, morphine, or tramadol) [81] may be added if there is a lack of response from the above agents. Topical (transdermal) therapies may include lidocaine $5 \%$ [79] or $8 \%$ capsaicin patches (both FDA approved for this condition) which has effects lasting up to 12 weeks after a single 60-min application [82]. Overall, pharmacological management is challenging with much of the treatment not being completely effective [83].

\section{Burning Mouth Syndrome}

Burning mouth syndrome (BMS) has a multiplicity of nomenclatures including stomatodynia, glossodynia, oral dysesthesia, or stomatopyrosis. It is an enigmatic pain condition whereby the pathophysiology is largely unknown. Data from several experimental models support the hypothesis that BMS is most probably neuropathic in origin [84]. The role of the peripheral and/or central nervous system(s) is supported by studies involving quantitative sensory testing and functional imaging methods [84]. BMS most commonly presents in postmenopausal females with reported prevalence rates in the general population varying from 0.7 to $15 \%[85,86]$ and being rather rare in individuals under 30 years of age [87]. 
For clinical purposes, BMS may be categorized into "primary BMS" or essential/idiopathic BMS for which a neuropathological cause is likely and "secondary BMS" resulting from local or systemic pathological conditions [88]. Primary BMS is a diagnosis of exclusion as it is not attributable to any underlying systemic or local factors [89]. Furthermore, typical characteristics manifested by the condition are a mild to severe burning sensation in the mucosa, dysgeusia, and xerostomia accompanied by a lack of clinical findings and normal results from laboratory testing and/or imaging studies. The subjective burning is routinely observed bilaterally, most frequently involving the anterior two thirds of the tongue, the dorsum and lateral borders of the tongue, the anterior hard palate, and the mucosa of the lower lip, and often presenting in more than one oral site [90]. Typically, BMS has a spontaneous onset lasting months to several years [89]. Spontaneous remission has been reported in only $3 \%$ of patients after 5 years of onset [91]. Burning symptoms are common upon awakening with intensification as the day progresses and climaxing in the evening. Aggravating factors responsible for burning intensification are personal stressors and fatigue and eating acidic/hot/spicy foods. Paradoxically, in about $50 \%$ of patients, oral intake/ stimulation and distraction reduce or alleviate the symptoms [92]. An association with anxiety, depression, and personality disorders has been reported especially in postmenopausal women [87], but it is unknown if pain initiated the psychological disorder or vice versa [93].

Management approaches include three strategies which may be employed singularly or in combination: behavioral strategies involving cognitive-behavioral approaches and/or group psychotherapy; topical therapies utilizing anxiolytics (clonazepam), anesthetics (lidocaine), antidepressants (doxepin), atypical analgesics (capsaicin), nonsteroidal antiinflammatory (benzydamine - not FDA approved for use in the USA), antimicrobials (lysozyme-lactoperoxidase), mucosal protectants (sucralfate, aloe vera, lycopene virgin oil), artificial sweeteners (sucralose), and low-level laser therapy; and systemic approaches employing various medications such as antidepressants (amitriptyline, imipramine, nortriptyline, desipramine, trazodone, paroxetine, sertraline, duloxetine, milnacipran), anxiolytics (clonazepam, diazepam, chlordiazepoxide), anticonvulsants (gabapentin, pregabalin, topiramate), antioxidants (alpha lipoic acid), atypical analgesics/antipsychotics (capsaicin, olanzipine: amisulpride, levosulpride - both medications are not FDA approved for use in the USA), histamine receptor antagonists (lafutidine - not FDA approved for use in the USA), monoamine oxidase inhibitors (moclobemide - not FDA approved for use in the USA), salivary stimulants (pilocarpaine), dopamine agonists (pramipexole), herbal supplements (hypericum perforatum or St. John's wort), and acupuncture. A recent randomized controlled trial indicated that systemic use of clonazepam should be considered as a first-line treatment [94].

\section{Conclusions}

Patients will present to their dental practitioner with the complaint of orofacial pain. In the majority of cases, the pain is likely dental in origin; however, occasionally, the pain may be of a neurogenous source. Therefore, dental practitioners must have a comprehensive understanding of neuropathic orofacial pains to avoid unnecessary dental procedures to the detriment of their patients. If a patient is suspected of having neuropathic pain, referral to a practitioner who has enhanced training and education regarding these conditions is prudent for further assessment and treatment.

\section{Compliance with Ethics Guidelines}

Conflict of Interest Janina Christoforou, Ramesh Balasubramaniam, and Gary D. Klasser have no conflict of interest.

Human and Animal Rights and Informed Consent This article does not contain any studies with human or animal subjects performed by any of the authors.

\section{References}

Papers of particular interest, published recently, have been highlighted as:

- Of major importance

1. IASP Taxonomy. In: International Association for the Study of Pain. IASP Publications. 2011. http://www.iasp-pain.org/ Taxonomy-Neuropathicpain. Accessed 16 Jan 2015.

2. Clark G. Persistent orodental pain, atypical odontalgia, and phantom tooth pain: when are they neuropathic disorders? J Calif Dent Assoc. 2006;34:599-609.

3. Marbach J. Phantom tooth pain: differential diagnosis and treatment. N Y State Dent J. 1993;59:28-33.

4. Scrivani S, Mathews E, Maciewicz R. Trigeminal neuralgia. Oral Surg Oral Med Oral Pathol Oral Radiol Endod. 2005;100:527-38.

5. Truelove E. Management issues of neuropathic trigeminal pain from a dental perspective. J Orofac Pain. 2004;18:374-80.

6. Edwards R. Individual differences in endogenous pain modulation as a risk factor for chronic pain. Neurology. 2005;65:437-43.

7. Singh M. In: Trigeminal Neuralgia. Medscape. 2014. http:// emedicine.medscape.com/article/1145144-overview. Accessed 27 Dec 2014.

8. Nurmikko T, Eldridge P. Trigeminal neuralgia — pathophysiology, diagnosis and current treatment. Br J Anaesth. 2001;87:117-32.

9. Jensen T, Rasmussen P, Reske-Nielsen E. Association of trigeminal neuralgia with multiple sclerosis: clinical and pathological features. Acta Neurol Scand. 1982;65:182-9.

10. Bornemann A, Bohl J, Hey O, Storkel S, Gamm H, Muller-Forell $\mathrm{W}$, et al. Amyloidoma of the gasserian ganglion as a cause of symptomatic neuralgia of the trigeminal nerve: report of three cases. J Neurol. 1993;241:10-4.

11. Coffey R, Fromm G. Familial trigeminal neuralgia and CharcotMarie-Tooth neuropathy. Report of two families and review. Surg Neurol. 1991;35:49-53. 
12. Sampathkumar P, Drage L, Martin D. Herpes zoster (shingles) and postherpetic neuralgia. Mayo Clin Proc. 2009;84(3):274-80.

13. Rhoton A. The cerebellopontine angle and posterior fossa cranial nerves by the retrosigmoid approach. Neurosurgery. 2000;47: S93-129.

14. Obermann M, Holle D, Katsarava Z. Trigeminal neuralgia and persistent idiopathic facial pain. Expert Rev Neurother. 2011;11: 1619-29.

15. Jurjevic A, Bralic M, Bucuk M, Tuskan-Mohar L, Coklo M, Bosnar A. Trigeminal neuralgia secondary to meningioma of petroclival localization. Coll Antropol. 2009;33:323-5.

16. Cheng T, Cascino T, Onofrio B. Comprehensive study of diagnosis and treatment of trigeminal neuralgia secondary to tumours. Neurology. 1993;43:2298-302.

17. Devor M, Amir R, Rappaport ZH. Pathophysiology of trigeminal neuralgia: the ignition hypothesis. Clin J Pain. 2002;18:4-13.

18. Obermann M, Rodriguez-Raecke R, Naegel S, Holle D, Mueller $\mathrm{D}$, Yoon MS, et al. Gray matter volume reduction reflects chronic pain in trigeminal neuralgia. Neuroimage. 2013;74:352-8.

19. Jorns T, Zakrzewska J. Evidence-based approach to the medical management of trigeminal neuralgia. Br J Neurosurg. 2007;21: 253-61.

20. Oesman C, Mooij J. Long-term follow-up of microvascular decompression for trigeminal neuralgia. Skull Base. 2011;21:31322.

21. Love S, Coakham H. Trigeminal neuralgia: pathology and pathogenesis. Brain. 2001;124:2347-60.

22. Kubicek GJ, Hall WA, Orner JB, Gerbi BJ, Dusenbery KE. Longterm follow-up of trigeminal neuralgia treatment using a linear accelerator. Stereotact Funct Neurosurg. 2004;82:244-9.

23. Henson CF, Goldman HW, Rosenwasser RH, Downes MB, Bednarz G, Pequignot EC, et al. Glycerol rhizotomy versus gamma knife radiosurgery for the treatment of trigeminal neuralgia: an analysis of patients treated at one institution. Int $\mathrm{J}$ Radiat Oncol Bio Phys. 2005;63:82-90.

24. Pradel W, Hlawitschka M, Eckelt U, Herzog R, Koch K. Cryosurgical treatment of genuine trigeminal neuralgia. $\mathrm{Br} \mathrm{J}$ Oral Maxillofac Surg. 2002;40:244-7.

25. Emril DR, Ho KY. Treatment of trigeminal neuralgia: role of radiofrequency ablation. J Pain Res. 2010;3:249-54.

26. Strojnik T, Smigoc T. Percutaneous trigeminal ganglion balloon compression rhizotomy: experience in 27 patients. Sci World J. 2012;2012:328936

27. Zakrzewska J, Patsalos P. Long-term cohort study comparing medical (oxcarbazepine) and surgical management of intractable trigeminal neuralgia. Pain. 2002;95:259-66.

28. Zakrzewska J, Lopez B, Kim S, Coakham H. Patient reports of satisfaction after microvascular decompression and partial sensory rhizotomy for trigeminal neuralgia. Neurosurgery. 2005;56:1304 11.

29. Katusic S, Williams D, Beard C, Bergstralh E, Kurland L. Incidence and clinical features of glossopharyngeal neuralgia. Neuroepidemiology. 1991;10:266-75.

30. Fischbach F, Lehmann T, Ricke J, Bruhn H. Vascular compression in glossopharyngeal neuralgia: demonstration by high-resolution MRI at 3 tesla. Neuroradiology. 2003;45:810-1.

31. Rushton J, Stevens J, Miller R. Glossopharyngeal (vagoglossopharyngeal) neuralgia: a study of 217 cases. Arch Neurol. 1981;38:201-5.

32. Minagar A, Sheremata W. Glossopharyngeal neuralgia and MS. Neurology. 2000;54:1368-70.

33. Rozen T. Trigeminal neuralgia and glossopharyngeal neuralgia. Neurol Clin. 2004;22:185-20.

34. Kandan S, Khan S, Jeyaretna D, Lhatoo S, Patel N, Coakham H. Neuralgia of the glossopharyngeal and vagal nerves: long-term outcome following surgical treatment and literature review. $\mathrm{Br} \mathrm{J}$ Neurosurg. 2010;24:441-6.

35. Martínez-Álvarez R, Martínez-Moreno N, Kusak M, Rey-Portolés G. Glossopharyngeal neuralgia and radiosurgery. J Neurosurg. 2014;121:S222-S5.

36. Loeser J. Bonica's management of pain. 3rd ed. Philadelphia: Lippincott: Williams \& Wilkins; 2001.

37. Trancredi A, Caputti F. Greater occipital neuralgia and arthrosis of C1-C2 lateral joint. Eur J Neurol. 2004;11:573-4.

38. Bogduk N. The anatomy and pathophysiology of neck pain. Phys Med Rehabil Clin N Am. 2011;22:367-82.

39. Vanelderen P, Lataster A, Levy R, Mekhail N, van Kleef M, Van Zundert J. Occipital neuralgia. Pain Pract. 2010;10:137-44.

40. Aguggia M. Typical facial neuralgias. Neurol Sci. 2005;26:S68 70.

41. Pulec J. Geniculate neuralgia: long-term results of surgical treatment. Ear Nose Throat J. 2002;81:30-3.

42. Lovely T, Jannetta P. Surgical management of geniculate neuralgia. Am J Otol. 1997;18:512-7.

43. Bruyn G. Superior laryngeal neuralgia. Cephalalgia. 1983;3:23540.

44. Dorsch J. Neurologic syndromes of the head and neck. Prim Care. 2014;41:133-49.

45. Takahashi SK, Suzuki M, Izuha A. Two cases of idiopathic superior laryngeal neuralgia treated by superior laryngeal nerve block with a high concentration of lidocaine. J Clin Anesth. 2007;19: 237-8.

46.• Benoliel R, Kahn J, Eliav E. Peripheral painful traumatic trigeminal neuropathies. Oral Dis. 2012;18:317-32. A comprehensive review of peripheral painful traumatic trigeminal neuropathies, including a treatment algorithm and alternative terminology in common use.

47. Woda A. Painful posttraumatic trigeminal neuropathy: a recently recognized entity. J Orofac Pain. 2013;27(2):97-8.

48. Jaaskelainen SK, Teerijoki-Oksa T, Virtanen A, Tenovuo O, Forssell H. Sensory regeneration following intraoperatively verified trigeminal nerve injury. Neurology. 2004;62:1951-7.

49. Benoliel R, Wilensky A, Tal M, Eliav E. Application of a proinflammatory agent to the orbital portion of the rat infraorbital nerve induces changes indicative of ongoing trigeminal pain. Pain. 2002;99:567-78.

50. Neumann S, Doubell T, Leslie T, Woolf C. Inflammatory pain hypersensitivity mediated by phenotypic switch in myelinated primary sensory neuron. Nature. 1996;384:360-4.

51. Finnerup N, Sindrup S, Jensen T. The evidence of pharmacological treatment of neuropathic pain. Pain. 2010;150:573-81.

52. Lopez-Lopez J, Estrugo-Devesa A, Jane-Salas E, Segura-Egea JJ, Chang TI. Medical treatment of post-dental extraction peripheral painful traumatic trigeminal neuropathy. Quintessence Int. 2013;44:703-6.

53. Klasser G. Management of persistent idiopathic facial pain. J Can Dent Assoc. 2013;79:d71.

54. Cornelissen P, van Kleef M, Mekhail N, Day M, van Zundert J. Evidence-based interventional pain medicine according to clinical diagnoses. 3. Persistent idiopathic facial pain. Pain Pract. 2009;9: 443-8.

55. Aghabeigi B, Feinmann C, Glover V, Goodwin B, Hannah P, Harris $\mathrm{M}$, et al. Tyramine conjugation deficit in patients with chronic idiopathic temporomandibular joint and orofacial pain. Pain. 1993;54:157-9.

56. Schmidt-Wilcke T, Hierlmeier S, Leinisch E. Altered regional brain morphology in patients with chronic facial pain. Headache. 2010;50:1278-85.

57. Derbyshire S, Jones A, Devani P, Friston K, Feinmann C, Harris $\mathrm{M}$, et al. Cerebral responses to pain in patients with atypical facial 
pain measured by positron emission tomography. J Neurol Neurosurg Psychiatry. 1994;57:1166-72.

58. Hagelberg N, Forssell H, Aalto S, Rinne J, Scheinin H, Taiminen $\mathrm{T}$, et al. Altered dopamine D2 receptor binding in atypical facial pain. Pain. 2003;106:43-8.

59. Zelenka M, Schafers M, Sommer C. Intraneural injection of interleukin-1beta and tumour necrosis factor-alpha into rat sciatic nerve at physiological doses induces signs of neuropathic pain. Pain. 2005;116:257-63.

60. Eliav E, Teich S, Nitzan D, El Raziq DA, Nahieli O, et al. Facial arthralgia and myalgia: can they be differentiated by trigeminal sensory assessment? Pain. 2003;104:481-90.

61. Benoliel R, Biron A, Quek S, Nahlieli O, Eliav E, Gracely R, et al. Trigeminal neurosensory changes following acute and chronic paranasal sinusitis. Quintessence Int. 2006;37:437-43.

62. Eliav E, Teich S, Benoliel R, Nahieli O, Lewkowicz AA, et al. Large myelinated nerve fiber hypersensitivity in oral malignancy. Oral Surg Oral Med Oral Path Oral Radiol Endod. 2002;94:45-50.

63. Benoliel R, Eliav E. Neuropathic orofacial pain. Oral Maxillofac Surg Clin North Am. 2008;20:237-54.

64. Lin F, Hadler JL. Epidemiology of primary varicella and herpes zoster hospitalizations: the pre-varicella vaccine era. J Infect Dis. 2013;181:1897-905.

65. Fekete T. A varicella-zoster virus vaccine reduced the burden of illness of herpes zoster in older adults. ACP J Club. 2005;143:61.

66. Rondaan C, de Haan A, Horst G, Hempel J, van Leer C, Bos N, et al. Altered cellular and humoral immunity to varicella-zoster virus in patients with autoimmune diseases. Arthritis Rheumatol. 2014;66:3122-8

67. Giller R, Bowden R, Levin M, Walker L, Tubergen D, Hayward A. Reduced cellular immunity to varicella zoster virus during treatment for acute lymphoblastic leukemia of childhood: in vitro studies of possible mechanisms. J Clin Immunol. 1986;6:472-80

68. Meyers J, Flournoy N, Thomas E. Cell-mediated immunity to varicella-zoster virus after allogeneic marrow transplant. J Infect Dis. 1980;141:479-87.

69. Caple J. Varicella-zoster virus vaccine: a review of its use in the prevention of herpes zoster in older adults. Drugs Today. 2006;42: $249-54$.

70. Coughlin S. Anxiety and depression: linkages with viral diseases. Public Health Rev. 2012;34:1-15.

71. Harpaz R, Ortega-Sanchez I, Seward J. Prevention of herpes zoster: recommendations of the Advisory Committee on Immunization Practices (ACIP). MMWR Recomm Rep. 2008;57:1-30.

72. Carmichael J. Treatment of herpes zoster and postherpetic neuralgia. Am Fam Physician. 1991;44:203-10.

73. Beutner K, Friedman D, Forszpaniak C, Andersen P, Wood M. Valaciclovir compared with acyclovir for improved therapy for herpes zoster in immunocompetent adults. Antimicrob Agents Chemother. 1995;39:1546-53.

74. Opstelten W, Zaal M. Managing opthalmic herpes zoster in primary care. BMJ. 2005;331:147-51.

75. Dworkin RH, Johnson RW, Breuer J, Gnann JW, Levin MJ, Backonja M, et al. Recommendations for the management of herpes zoster. Clin Infect Dis. 2007;44:S1-26.

76. Manzoni GC, Torelli P. Epidemiology of typical and atypical craniofacial neuralgias. Neurol Sci. 2005;26:s65-7.

77. Oxman MN, Levin MJ, Johnson GR, Schmader KE, Straus SE, Gelb LD, et al. A vaccine to prevent herpes zoster and postherpetic neuralgia in older adults. N Engl J Med. 2005;352:2271-84.

78. Leme LE. Vaccines for preventing herpes zoster in older adults. Rev Paul Med. 2014;132:255.

79. Dworkin R, Backonja M, Rowbotham M, Allen R, Argoff C, Bennett $G$, et al. Advances in neuropathic pain: diagnosis, mechanisms, and treatment recommendations. Arch Neurol. 2003;60:1524-34.

80. Frampton J, Foster R. Pregabalin in the treatment of postherpetic neuralgia. Drugs. 2005;65:111-8.

81. Wu C, Raja S. An update on the treatment of postherpetic neuralgia. J Pain. 2008;9:S19-30.

82. Wallace MS, Pappagallo M. Qutenza: a capsaicin $8 \%$ patch for the management of postherpetic neuralgia. Expert Rev Neurother. 2011;11:15-27.

83. Philip A, Thakur R. Post herpetic neuralgia. J Palliat Med. 2011;14:765-73.

84. Jaaskelainen S. Pathophysiology of primary burning mouth syndrome. Clin Neurophysiol. 2012;123:71-7.

85. Lipton J, Ship J, Larach-Robinson D. Estimated prevalence and distribution of reported orofacial pain in the United States. J Am Dent Assoc. 1993;124:115-21.

86. Tammiala-Salonenm T, Hiidenkari T, Parvinen T. Burning mouth in a Finnish adult population. Community Dent Oral Epidemiol. 1993;21:67-71.

87. Bergdahl M, Bergdahl J. Burning mouth syndrome: prevalence and associated factors. J Oral Pathol Med. 1999;28:350-4.

88. Scala A, Checchi L, Montevecchi M, Marini I, Giamberardino M. Update on burning mouth syndrome: overview and patient management. Crit Rev Oral Biol Med. 2003;14:275-91.

89. Rhodus N, Carlson C, Miller C. Burning mouth (syndrome) disorder. Quintessence Int. 2003;34:587-93.

90. Grushka M. Clinical features of burning mouth syndrome. Oral Surg Oral Med Oral Pathol. 1987;63:30-6.

91. Sardella A, Lodi G, Demarosi F, Bez C, Cassano S, Carrassi A. Burning mouth syndrome: a retrospective study investigating spontaneous remission and response to treatments. Oral Dis. 2006;12:152-5.

92. Suarez P, Clark G. Burning mouth syndrome: an update on diagnosis and treatment methods. J Calif Dent Assoc. 2006;34:61122 .

93. Schiavone V, Adamo D, Ventrella G, Morlino M, De Notaris E, Ravel M, et al. Anxiety, depression, and pain in burning mouth syndrome: first chicken or egg? Headache. 2012;52:1019-25.

94. Heckmann S, Kirchner E, Grushka M, Wichmann M, Hummel T. A double-blind study on clonazepam in patients with burning mouth syndrome. Laryngoscope. 2012;122:813-6.

95. Taylor J, Brauer S, Espir M. Long-term treatment of trigeminal neuralgia. Postgrad Med J. 1981;57:16-8.

96. Liebel J, Menger N, Langohr H. Oxcarbazepine in Behandlung der Trigeminusneuralgie. Nervenheilkunde. 2001;20:461-5.

97. Zakrzewska J, Chaudhry Z, Nurmikko T, Patton D, Mullens E. Lamotrigine (lamictal) in refractory trigeminal neuralgia: results from a double-blind placebo controlled crossover trial. Pain. 1997;73:223-30.

98. Fromm G, Terrence C, Chattha A. Baclofen in the treatment of trigeminal neuralgia: double-blind study and long-term follow-up. Ann Neurol. 1984;15:240-4.

99. Cheshire Jr WP. Defining the role for gabapentin in the treatment of trigeminal neuralgia: a retrospective study. J Pain. 2002;3:13742.

100. Obermann M, Yoon MS, Sensen K, Maschke M, Diener HC, Katsarava Z. Efficacy of pregabalin in the treatment of trigeminal neuralgia. Cephalalgia. 2008;28:174-81.

101. Zvartau-Hind M, Din M, Gilani A, Lisak R, Khan O. Topiramate relieves refractory trigeminal neuralgia in MS patients. Neurology. 2000;55:1587-8

102. Kanai A, Saito M, Hoka S. Subcutaneous sumatriptan for refractory trigeminal neuralgia. Headache. 2006;46:577-82.

103. Verma G. Role of botulinum toxin type-A (BTX-A) in the management of trigeminal neuralgia. Pain Res Treat. 2013;2013: 831094. 
104. Persaud R, Garas G, Silva S, Stamatoglou C, Chatrath P, Patel K. An evidence-based review of botulinum toxin (Botox) applications in non-cosmetic head and neck conditions. JRSM Short Rep. 2013;4:10.

105. Kouzounias K, Schechtmann G, Lind G, Winter J, Linderoth B. Factors that influence outcome of percutaneous balloon compression in the treatment of trigeminal neuralgia. Neurosurgery. 2010;67:925-34.

106. Slettebo H, Hirschberg H, Lindegaard K. Long-term results after percutaneous retrogasserian glycerol rhizotomy in patients with trigeminal neuralgia. Acta Neurochir. 1993;122:231-5.
107. Zakrzewska J. Cryotherapy in the management of paroxysmal trigeminal neuralgia. J Neurol Neurosurg Psychiatry. 1987;50: 485-7.

108. Kanpolat Y, Savas A, Bekar A, Berk C. Percutaneous controlled radiofrequency trigeminal rhizotomy for the treatment of idiopathic trigeminal neuralgia: 25-year experience with 1,600 patients. Neurosurgery. 2001;48:524-32.

109. Lopez B, Hamlyn P, Zakrzewska J. Stereotactic radiosurgery for primary trigeminal neuralgia: state of the evidence and recommendation for future reports. J Neurol Neurosurg Psychiatry. 2004;75: 1019-24. 